\title{
Calculated the diffuse and direct parts of global solar radiation in Baghdad city for the period (1983-2005) depending on clearness index by applying the \\ two world models of Liu -Jordan
}

Gheidaa Sabeeh Al-Hassany

Remote sensing Unit, College of Science, University of Baghdad,, Baghdad, Iraq

E-mail: Geda_sabeh@yahoo.com

\begin{abstract}
In this paper solar radiation was studied over a region of Baghdad (Latitude $33.3^{\circ}$ and longitude $44.4^{\circ}$ ). The two parts of global solar radiation: diffuse and direct solar radiation were estimated depending on the clearance index of measured data (Average Monthly mean global solar radiation). Metrological data of measured (average monthly mean diffuse and direct solar radiation) were used to comparison the results and show the agreement between them. Results are determined by applying Liu and Jordan two models (1960). Excel 2007program is used in calculation, graphics and comparison the results.
\end{abstract}

Key words

solar radiation, clearness index, diffuse fraction, direct fraction.

Article info.

Received: Jun. 2014

Accepted: Oct. 2014

Published: Dec. 2014

حساب الجزأين المنتشر والمباشر للإشعاع الثمسي الإجمالي لمدينة بغداد للفترة (1983-2005) بالاعتماد على دليل الوضوحية بتطبيق موديلي ليو- جوردون العالميان غيداء صبيح الحسني وحدة الاستشعار عن بعد، كلية العلوم، جامعة بغداد، بغداد، العراق

في هذا البحث تمت دراسة الإشعاع الثمسي فوق منطقة بغداد (خط عرض 33.3 وخط طول

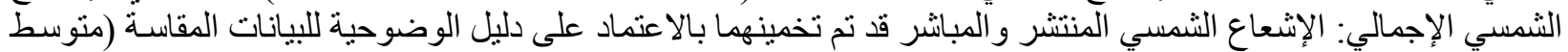

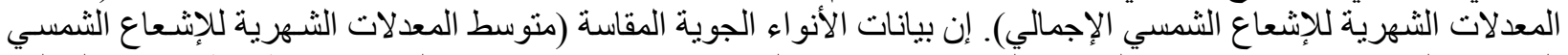

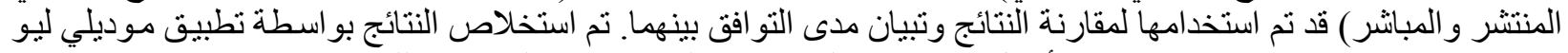
- جوردون (1960). تم استخدام برنامج أكسل 2007 في الحسابات و المخططات و المقارنات للنتائج.

\section{Introduction}

The radiation from the sun is the primary natural energy source of the planet Earth. Other natural energy sources are the cosmic radiation, the natural terrestrial radioactivity and the geothermal heat flux from the interior to the surface of the Earth, but these sources are energetically negligible as compared to solar radiation. When the spoken is of solar radiation, It means the electromagnetic radiation of the Sun. The energy distribution of electromagnetic radiation over different wavelength is called Spectrum. The electromagnetic spectrum is divided into different spectral ranges (Fig.1). 


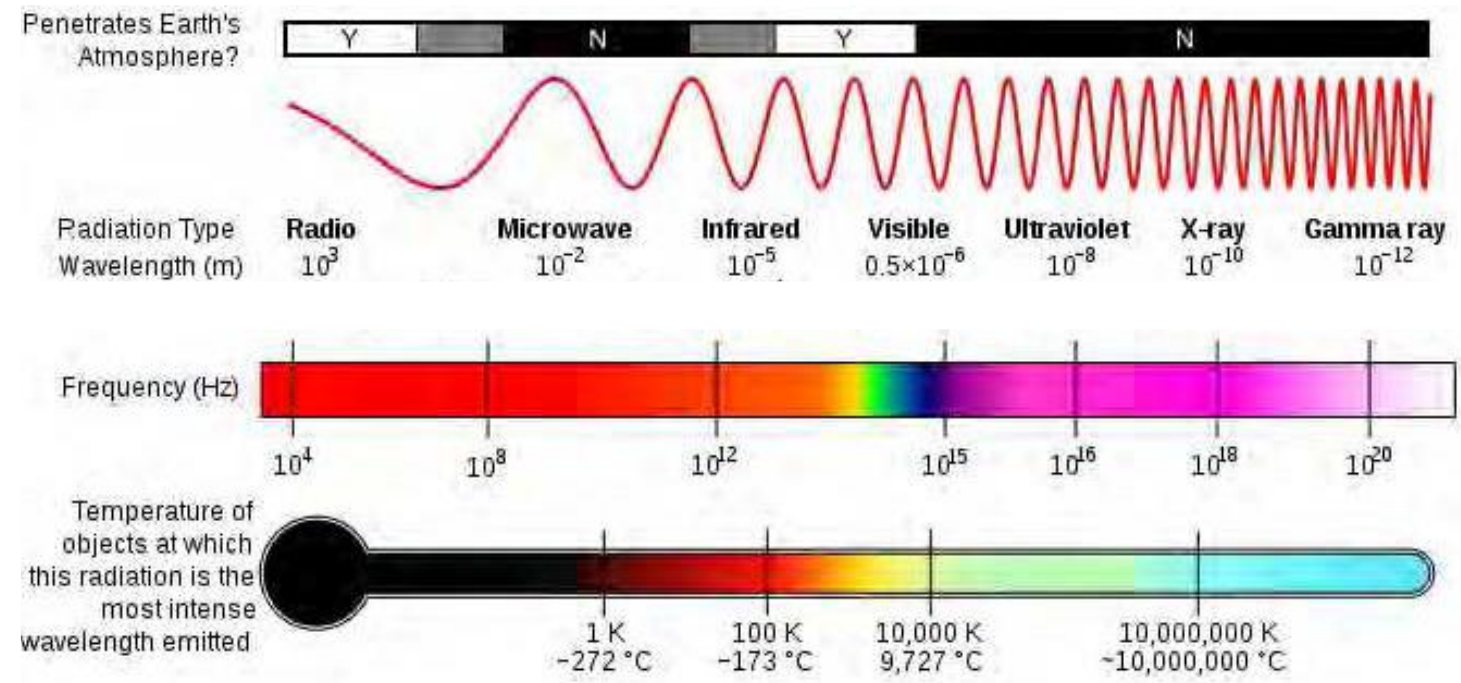

Fig.1: Spectral ranges of electromagnetic radiation[1].

The quantity of solar radiation reaching the earth's surface varies dramatically as a function of changing atmospheric condition as well as the changing position of the sun through the day [2].

Solar radiation received at the surface is of primary importance for the purpose of building solar energy devices, estimating crop productivity, etc. However, direct measuring is not available in many cases, so numerical technique becomes aneffective alternative to estimate global radiation through observed meteorological data.

\subsection{Solar radiation}

The solar radiation, through atmosphere, reaching the earth's surface can be classified into two components: beam radiation and diffuse radiation. Beam radiation is the solar radiation propagating along the line joining the receiving surface and the sun. It is also referred to as direct radiation. Diffuse radiation is the solar radiation scattered by aerosols, dust and molecules, it does not have a unique direction. The total radiation is the sum of the beam and diffuses radiation and is sometimes referred to as the global radiation. When the amount of diffuse radiation reaching the earth's surface is less than or equal to $25 \%$ of global radiation, the sky is termed as clear sky.[3].

\subsection{Monthly variation of clearness index}

Clearness index $\left(K_{t}\right)$ is defined as the ratio of the observation (measured horizontal terrestrial solar radiation) $\left(I_{t}\right)$, to the calculated (predicted horizontal extraterrestrial solar radiation) $\left(I_{o}\right)$.

Clearness index is a measure of solar radiation extinction in the atmosphere, which includes effects due to clouds but also effects due to radiation interaction with other atmospheric constituents. To develop the model for the clearness index, the insolation on ahorizontal surface for a few locations is measured over a period of time encompassing all seasons and climatic conditions. Different values of the clearness index at different stations may be as a result of different atmospheric contents of water vapour and aerosols. It can be seen from the above expressions that the extra-terrestrial horizontal insolation is a function of latitude and the day of year only. Hence, it can be calculated for any location for any given day. However, the calculated insolation does 
not take any atmospheric effects into account.[1]

$$
K_{t}=\frac{I_{t}}{I_{o}}
$$

Where: $I_{t}$ is the measured horizontal terrestrial solar radiation.

$I_{o}$ is the predicted horizontal extraterrestrial solar radiation.

\subsection{Variation of diffuse solar radiation}

Several models for estimating the diffuse component based on the pioneer works of Angstrom (1924) and Liu and Jordan (1960). These models are usually expressed in either linear or polynomial fittings relating the diffuse fraction $\left(I_{d}\right)$ with the clearness index and combining both clearness index $\left(K_{t}\right)$ and relative sunshine duration to derive empirical models to estimate hourly, daily and monthly diffuse solar radiation from values of the global solar radiation. The diffuse solar radiation $I_{d}$ can be estimated by an empirical formula which correlates the diffuse solar radiation component $I_{d}$ to the daily total radiation $I$. The ratio, $I_{d} / I$, therefore, is an appropriate parameter to define a coefficient, that is, cloudiness or turbidity of the atmosphere [1].

Values of global and diffuse radiations for individual hours are essential for research and engineering applications. Hourly global radiations on horizontal surfaces are available for many stations, but relatively few stations measure the hourly diffuse radiation. Decomposition models have, therefore, been developed to predict the diffuse radiation using the measured global data.

The models are based on the correlations between the clearness index $\left(K_{t}\right)$, the diffuse fraction $K_{d}$, the diffuse coefficient $K_{D}$ or the direct transmittance $K_{b}$ all are dimensionless where:

$$
K_{t}=\frac{I_{t}}{I_{o}}, K_{d}=\frac{I_{d}}{I_{t}}, K_{D}=\frac{I_{d}}{I_{o}}, K_{b}=\frac{I_{b}}{I_{o}}
$$

$I_{t}, I_{b}, I_{d}$ and $I_{o}$ being the global, direct, diffuse and extraterrestrial irradiances, respectively, on a horizontal surface (all in $\mathrm{MJ} \mathrm{m}^{-2}$ ) [4].

\subsection{Liu and Jordan model}

The relationships permitting the determination, for a horizontal surface, of the instantaneous intensity of diffuse radiation on clear days, the long-term average hourly and daily sums of diffuse radiation, and the daily sums of diffuse radiation for various categories of days of differing degrees of cloudiness, with data from 98localities in the USA and Canada (19_ to 55_N latitude), were studied by Liu and Jordan. In Liu and Jordan model, the transmission coefficient for total radiation on a horizontal surface is given by the intensity of total radiation (i.e. direct Ib plus diffuse Id) incident upon a horizontal surface It divided by the intensity of solar radiation incident upon a horizontal surface outside the atmosphere of the Earth Io. The correlation between the intensities of direct and total radiations on clear days is given by[5]

$$
\begin{aligned}
& k_{\mathrm{D}}=0.271-0.2939 k_{\mathrm{b}} \\
& k_{\mathrm{t}}=\left(I_{\mathrm{b}}+I_{\mathrm{D}}\right) / I_{\mathrm{o}}=k_{\mathrm{b}}+k_{\mathrm{D}} \\
& k_{\mathrm{D}}=0.384-0.416 k_{\mathrm{t}}
\end{aligned}
$$

\section{Sunshine regions}

\subsection{Iraqi geography}

Iraq is located in the Middle East between latitudes $29^{\circ} 5^{\prime}$ and $37^{\circ} 22^{\prime} \mathrm{N}$ and longitudes $38^{\circ} 45^{\prime}$ and $48^{\circ} 45^{\prime}$ Elevation; It is bounded By: Turkey to the north, Iran to 
the east, Jordan, Syria and the Saudi Arabia to the west, and the Arabian Gulf, Kuwait and Saudi Arabia to the south.

\subsubsection{Weather in Iraq}

Iraq as a Middle Eastern country is one of those countries which are situated on yellow belt of earth that can receive the maximum light during the day and different months in the year. Iraq climate describe as hot weather in summer and cold in the winter season. A typical meteorological data set is not available in Iraq, mainly due to the lack of sufficient raw data. [6].

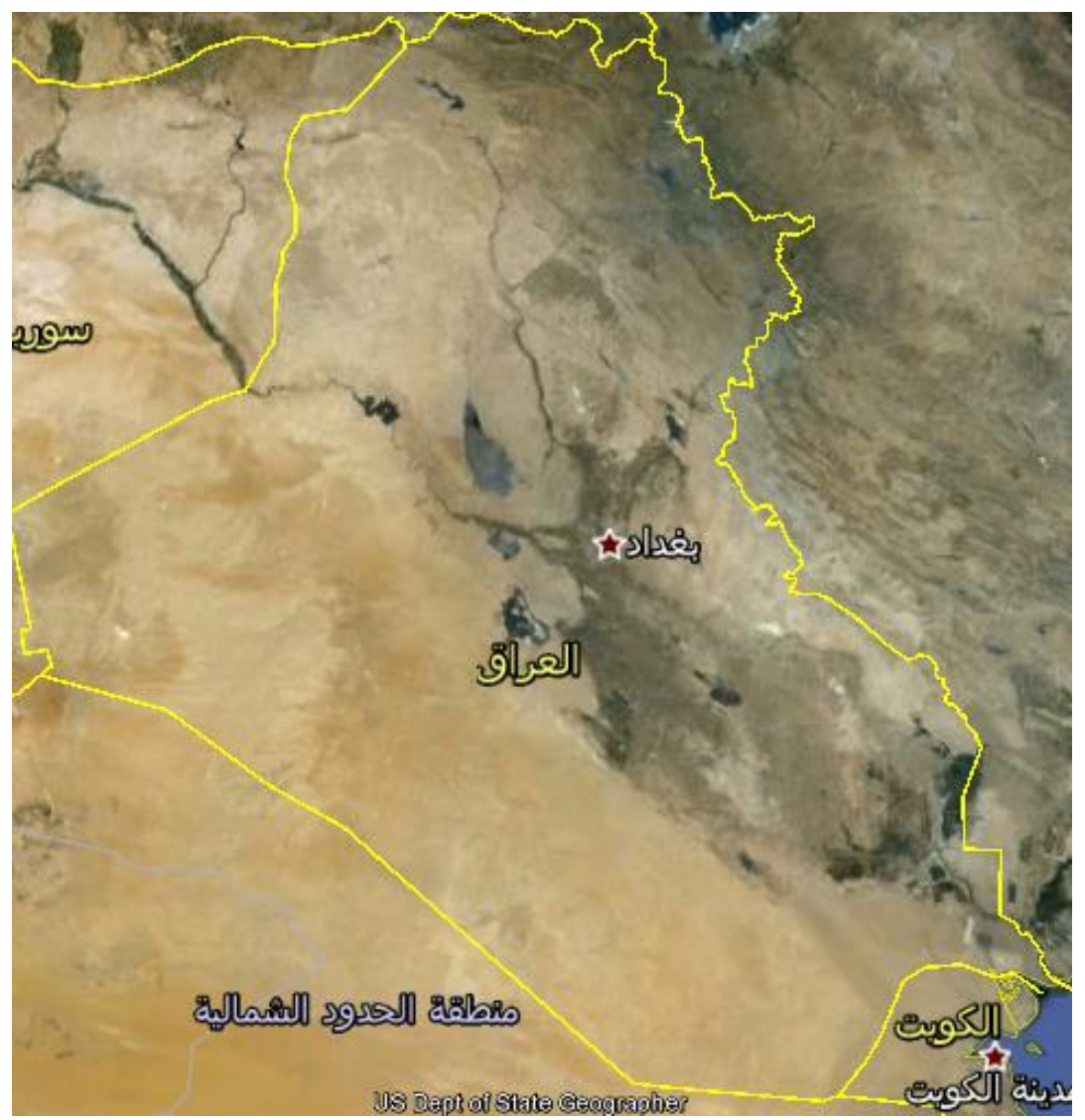

Fig. 2: Illustrated Iraq country region and Baghdad city location.

\subsection{Baghdad geography}

Baghdad is the capital of the Republic of Iraq, Located along the Tigris River. Baghdad is situated at $33.34^{\circ}$ North latitude, $44.4^{\circ}$ East longitude and 41 meters elevation above the sea level. Baghdad is a very large town in Iraq.

\section{Methodology}

Metrological data (measured average monthly mean global solar radiation for Baghdad at a period (1982-2000)) was used in this paper to derive direct and diffuse solar radiation. Also NASA measured metrological data (average monthly mean diffuse and direct solar radiation for a period (1983-2005)) (as shown in Table 1 and Fig. 3) were used to comparison the results and show the agreement between them. 


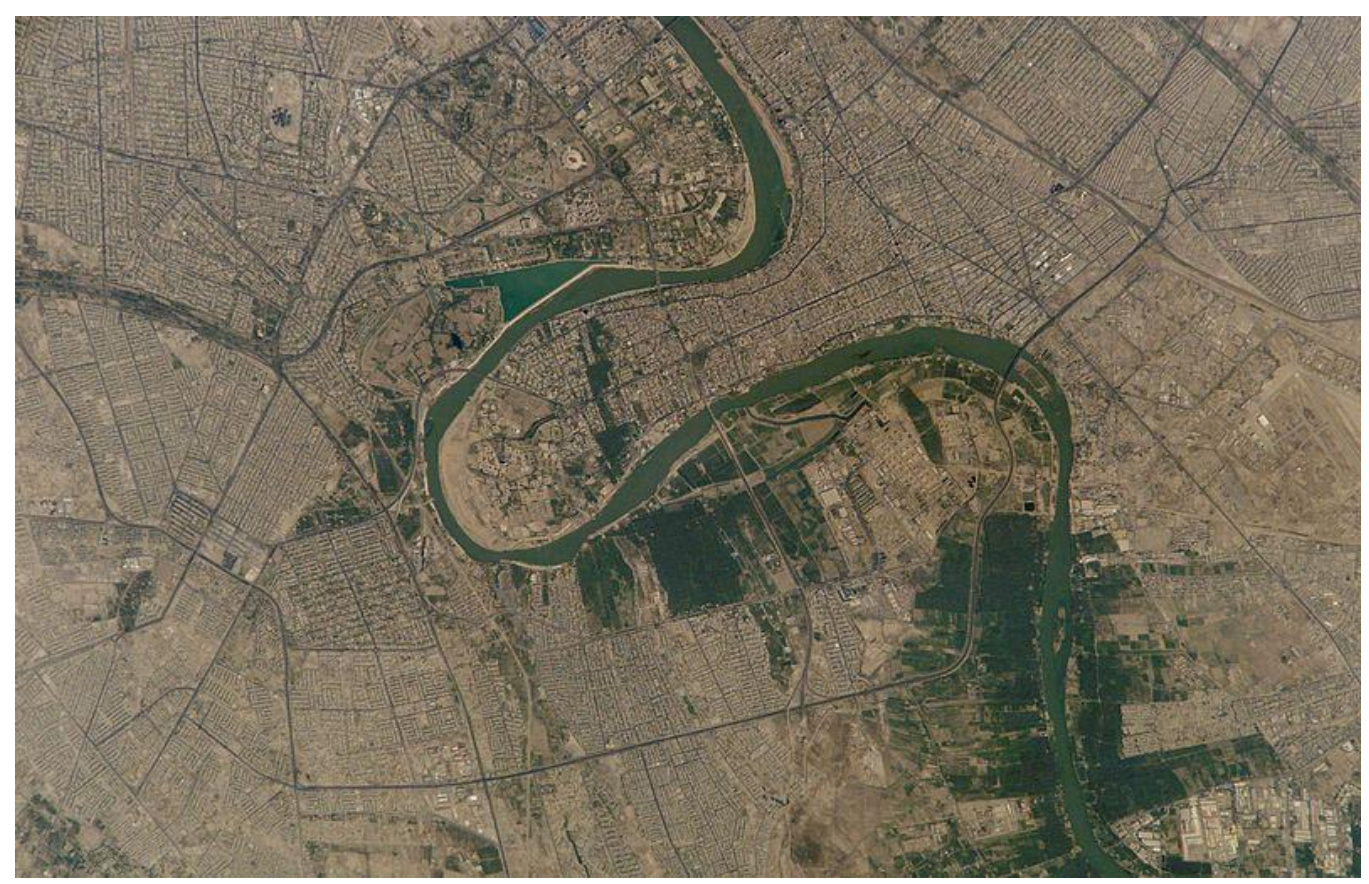

Fig. 2: Illustrated a center region of Baghdad city location.

Two models were applied to Baghdad to estimate the diffuse and direct solar radiation:

3.1 Liu and Jordan model was applied on Baghdad city in this work (because Baghdad city is located at the latitude $\left(33.34^{\circ}\right)$, in the range of the Latitude of the world locations that the model was applied in (19_ to 55_N latitude) to calculate diffuse and direct parts of measured global solar radiation at 2008 as following below:

1. The clearness index $K_{t}$ (dimensionless) was calculated by dividing the mean of monthly measured global solar radiation $I_{t}$ to the extraterrestrial solar radiation $I_{o}$ as shown in Table 1.

2. The clearness index $K_{t}$ was applied in Equation (4) and the diffuse coefficient $K_{D}$ (dimensionless), was determined as shown in Table 2.

3. Equation (2) was applied to determined the direct transmittance $K_{b}$ (dimensionless) as shown in Table 2.
4. Equation (1) was applied on $K_{b}$ to determined $K_{D}$ again to experiment the results of equation (4) (the reality of the determined the values of $K_{D}$ first) in Liu and Jordan model then when the results (from the two equations (2 and 4)) were comparison, the values were closely to each other.

The resulted $K_{D}$ from equation (4) was signaled as $K_{D 1}$ and $K_{D 2}$ to that results from equation (2). As shown in Table 4 and Fig.4.

5.The accuracy of the estimated values was tested by calculating the Mean Bias Error (MBE), the Root Mean Square Bias Error (RMSE) as shown in Table 6.

The expressions for the MBE $\left(\mathrm{MJ} \cdot \mathrm{m}^{-2} \mathrm{day}^{-1}\right)$ and RMSE (MJ.m ${ }^{-2}$ day $^{-1}$ ) [7] as follows:

$$
\begin{aligned}
& R M S E=\left(\left[\sum\left(I_{c a l .}-I_{a b s .}\right)^{2}\right] / M\right)^{1 / 2} \\
& M B E=\left[\sum_{i=1}^{M}\left(I_{c a l}-I_{a b s}\right)\right] / M
\end{aligned}
$$

Where $I_{c a l}$ : The calculated solar radiation. $I_{\text {obs. }}:$ The observed solar radiation. 
$M$ :No. of observation.

The Mean Bias Error gives an idea of the divergence between the monthly average daily radiation values estimated by the model used and the measured value. A positive value shows over estimation and a negative value is under estimation. Over estimation of an individual observation will cancel under estimation in a separate observation. It gives the long term performance of the correlation by allowing a comparison of the actual deviation between calculated and measured values term by term.

The Root Mean Bias Error yields the same idea of the divergence between the monthly average daily radiation values estimated by the model used and the measured values as given by MBE. However the information is relevant to the short-term performance. The ideal value for $\mathrm{MBE}$ would be Zero. RSME can never be negative and the lower the value the more accurate the estimate.

\section{Results and discussions}

For this study, Baghdad city at the center of Iraq was chosen to calculate the components of the global solar radiation by applying Liu and Jordan two models (depended on the latitude). The obtained results by these theoretical methods were comparison with the real data (measured data). The measured data are shown in Table 1 and illustrated in Fig. 3.

Then the correlation between $K_{t}, K_{D 1}$, $K_{D 2}, K_{b}$ are illustrated in Figure 4.

As shown in Fig. 5 and 6 a comparison between the calculated diffuse, direct solar radiation and the ratio $I_{d} / I_{b}$, $I_{d} / I_{t}$ and $I_{b} / I_{t}$ were illustrated.

In Table 5 the final results were obtained (the values of the calculated and measured $I_{d}$ and $I_{b}$ ) and Fig. 7 illustrated the calculated and measured values of diffuse and direct solar radiation.

Generally the two models gives a successful and closely results were obtained between measured and calculated values as shown in table 6the Mean Bias Error (MBE) and the Root Mean Square Bias Error (RMSE) were applied to test the quality of the calculated values of diffuse and direct solar radiation.

Then as shown in Fig. 7 the best results in calculated $I_{d}$ were appeared at the months: MAR, SEP, OCT and NOV.

And the best results in calculated $I_{b}$ were appeared at the months: AUG, MAR, SEP, OCT and NOV.

Table1: Extraterrestrial solar radiation and a metrological measured data (average monthly mean global, diffuse and direct solar radiation).

\begin{tabular}{|c|c|c|c|c|}
\hline Month & $I_{o}$ & $I_{t(\text { avg. })}$ & $I_{d \text { (avg.) }}$ & $I_{b(\text { avg. })}$ \\
\hline JAN & 18.77237 & 7.81911 & 2.573655 & 5.706801 \\
\hline FEB & 23.56372 & 11.08018 & 3.303183 & 8.798478 \\
\hline MAR & 30.10203 & 15.13341 & 4.882802 & 11.4369 \\
\hline APR & 36.48675 & 19.35763 & 7.210699 & 12.92973 \\
\hline MAY & 40.93584 & 23.11891 & 8.238137 & 16.77627 \\
\hline JUN & 42.81599 & 26.82848 & 7.712122 & 22.43464 \\
\hline JUL & 41.94486 & 25.99446 & 7.983688 & 19.14535 \\
\hline AUG & 38.33927 & 22.81493 & 6.335531 & 18.43754 \\
\hline SEP & 32.39337 & 18.32308 & 5.135813 & 13.61666 \\
\hline OCT & 25.53175 & 13.01779 & 4.1056 & 8.180331 \\
\hline NOV & 19.87673 & 8.681024 & 2.958793 & 5.519288 \\
\hline DEC & 17.34823 & 6.851588 & 2.402869 & 4.751126 \\
\hline
\end{tabular}


Table 2: Clearance index was applied in equation (5) for Baghdad city at a period (1983-2005) and Jordan model was applied to calculate $K_{D}, I_{d}, K_{b}, I_{b}$ and $I_{d} / I_{b}$.

\begin{tabular}{|c|c|c|c|c|c|c|c|c|}
\hline 䒿 & $I_{o}$ & $I_{t}$ & $K_{t}=I_{t} / I_{o}$ & $\begin{array}{l}K_{D}=0.384 \\
-0.416 K_{t}\end{array}$ & $I_{d}=K_{D} * I_{0}$ & $K_{b}=K_{t}-K_{D}$ & $I_{b}=K_{b} * I_{0}$ & $I_{d} / I_{b}$ \\
\hline JAN & 0 & 7.81911 & 065 & 2120 & 4.015641 & 0.194953 & 3.659723 & 1.097253 \\
\hline FEB & 23.5637 & 1.08018 & 0.465742 & 0.190251 & 4.483024 & 0.275491 & 6.491601 & 0.690588 \\
\hline MAR & 30.102 & 15.13341 & 0.514276 & 0.170061 & 5.11919 & 0.344214 & 10.36155 & 0.494056 \\
\hline APR & 36.4868 & 19.35763 & 0.551905 & 0.154408 & 5.633828 & 0.397498 & 14.50339 & 0.388449 \\
\hline MAY & 40.9358 & 23.11891 & 0.587881 & 0.139442 & 5.708158 & 0.448439 & 18.35724 & 0.310949 \\
\hline JUN & 42.816 & 26.82848 & 0.623748 & 0.124521 & 5.331477 & 0.499228 & 21.37493 & 0.249427 \\
\hline JUL & 41.9449 & 25.99446 & 0.626748 & 0.123273 & 5.170661 & 0.503475 & 21.1182 & 0.244844 \\
\hline $\mathbf{A U G}$ & 38.3393 & 22.81493 & 0.617975 & 0.126922 & 4.866113 & 0.491053 & 18.8266 & 0.25847 \\
\hline SEP & 32.3934 & 18.32308 & 0.579693 & 0.142848 & 4.627324 & 0.436845 & 14.15088 & 0.326999 \\
\hline OCT & 25.5317 & 13.01779 & 0.524883 & 0.165649 & 4.229303 & 0.359234 & 9.171867 & 0.461117 \\
\hline NOV & 19.8767 & 8.681024 & 237 & 0.197949 & 3.934584 & 0.249288 & 4.955029 & 0.794059 \\
\hline DEC & 17.3482 & 6.851588 & 0.385492 & 0.223635 & 3.879675 & 0.161857 & 2.807931 & 1.381685 \\
\hline
\end{tabular}

Table 3: The direct transmittance $\mathrm{kb}$ resulted from equation (3) was applied in equation (2).

\begin{tabular}{|c|c|c|c|c|}
\hline Month & $K_{b}=K_{t}-K_{D}$ & $\begin{array}{c}K_{D 2}=0.271- \\
0.2939 K_{b}\end{array}$ & $\begin{array}{c}K_{D 1}=0.384- \\
0.416 K_{t}\end{array}$ & $\left|K_{D 1}-K_{D 2}\right|$ \\
\hline JAN & 0.194953 & 0.213703 & 0.213912 & 0.000209 \\
\hline FEB & 0.275491 & 0.190033 & 0.190251 & 0.000218 \\
\hline MAR & 0.344214 & 0.169835 & 0.170061 & 0.000226 \\
\hline APR & 0.397498 & 0.154175 & 0.154408 & 0.000232 \\
\hline MAY & 0.448439 & 0.139204 & 0.139442 & 0.000238 \\
\hline JUN & 0.499228 & 0.124277 & 0.124521 & 0.000244 \\
\hline JUL & 0.503475 & 0.123029 & 0.123273 & 0.000244 \\
\hline AUG & 0.491053 & 0.12668 & 0.126922 & 0.000243 \\
\hline SEP & 0.436845 & 0.142611 & 0.142848 & 0.000237 \\
\hline OCT & 0.359234 & 0.165421 & 0.165649 & 0.000228 \\
\hline NOV & 0.249288 & 0.197734 & 0.197949 & 0.000215 \\
\hline DEC & 0.161857 & 0.22343 & 0.223635 & 0.000205 \\
\hline
\end{tabular}


Table 4: The average monthly mean of diffuse fraction $I_{d} / I_{t}$ and direct fraction $I_{b} / I_{t}$.

\begin{tabular}{|c|c|c|}
\hline Month & $I_{d} / I_{t}$ & $I_{b} / I_{t}$ \\
\hline JAN & 0.523186 & 0.476814 \\
\hline FEB & 0.40849 & 0.59151 \\
\hline MAR & 0.330681 & 0.669319 \\
\hline APR & 0.279772 & 0.720228 \\
\hline MAY & 0.237194 & 0.762806 \\
\hline JUN & 0.199633 & 0.800367 \\
\hline JUL & 0.196686 & 0.803314 \\
\hline AUG & 0.205384 & 0.794616 \\
\hline SEP & 0.24642 & 0.75358 \\
\hline OCT & 0.315592 & 0.684408 \\
\hline NOV & 0.442605 & 0.557395 \\
\hline DEC & 0.580129 & 0.419871 \\
\hline
\end{tabular}

Table 5: The values of the calculated and measured $I_{d}$ and $I_{b}$.

\begin{tabular}{|c|c|c|c|c|}
\hline Month & Calculated $I_{d}$ & Measured $I_{d}$ & Calculated $I_{b}$ & Measured $I_{b}$ \\
\hline JAN & 4.015641 & 2.573655 & 3.659723 & 5.706801 \\
\hline FEB & 4.483024 & 3.303183 & 6.491601 & 8.798478 \\
\hline MAR & 5.11919 & 4.882802 & 10.36155 & 11.4369 \\
\hline APR & 5.633828 & 7.210699 & 14.50339 & 12.92973 \\
\hline MAY & 5.708158 & 8.238137 & 18.35724 & 16.77627 \\
\hline JUN & 5.331477 & 7.712122 & 21.37493 & 22.43464 \\
\hline JUL & 5.170661 & 7.983688 & 21.1182 & 19.14535 \\
\hline AUG & 4.866113 & 6.335531 & 18.8266 & 18.43754 \\
\hline SEP & 4.627324 & 5.135813 & 14.15088 & 13.61666 \\
\hline OCT & 4.229303 & 4.1056 & 9.171867 & 8.180331 \\
\hline NOV & 3.934584 & 2.958793 & 4.955029 & 5.519288 \\
\hline DEC & 3.879675 & 2.402869 & 2.807931 & 4.751126 \\
\hline
\end{tabular}

Table 6: The mean bias error (MBE), the root mean square bias error (RMSE) were applied to test the quality of the calculated values of diffuse and direct solar radiation.

\begin{tabular}{|c|c|c|}
\hline \multirow{2}{*}{ MBE } & $\left(I_{d}\right.$ meas. $) \&\left(I_{d}\right.$ cal. $)$ & -0.48699 \\
\cline { 2 - 3 } & $\left(I_{b}\right.$ meas. $) \&\left(I_{b}\right.$ cal. $)$ & -1.6285 \\
\hline \multirow{2}{*}{ RMSE } & $\left(I_{d}\right.$ meas. $) \&\left(I_{d}\right.$ cal. $)$ & 1.621761 \\
\cline { 2 - 3 } & $\left(I_{b}\right.$ meas. $) \&\left(I_{b}\right.$ cal. $)$ & 1.476873 \\
\hline
\end{tabular}




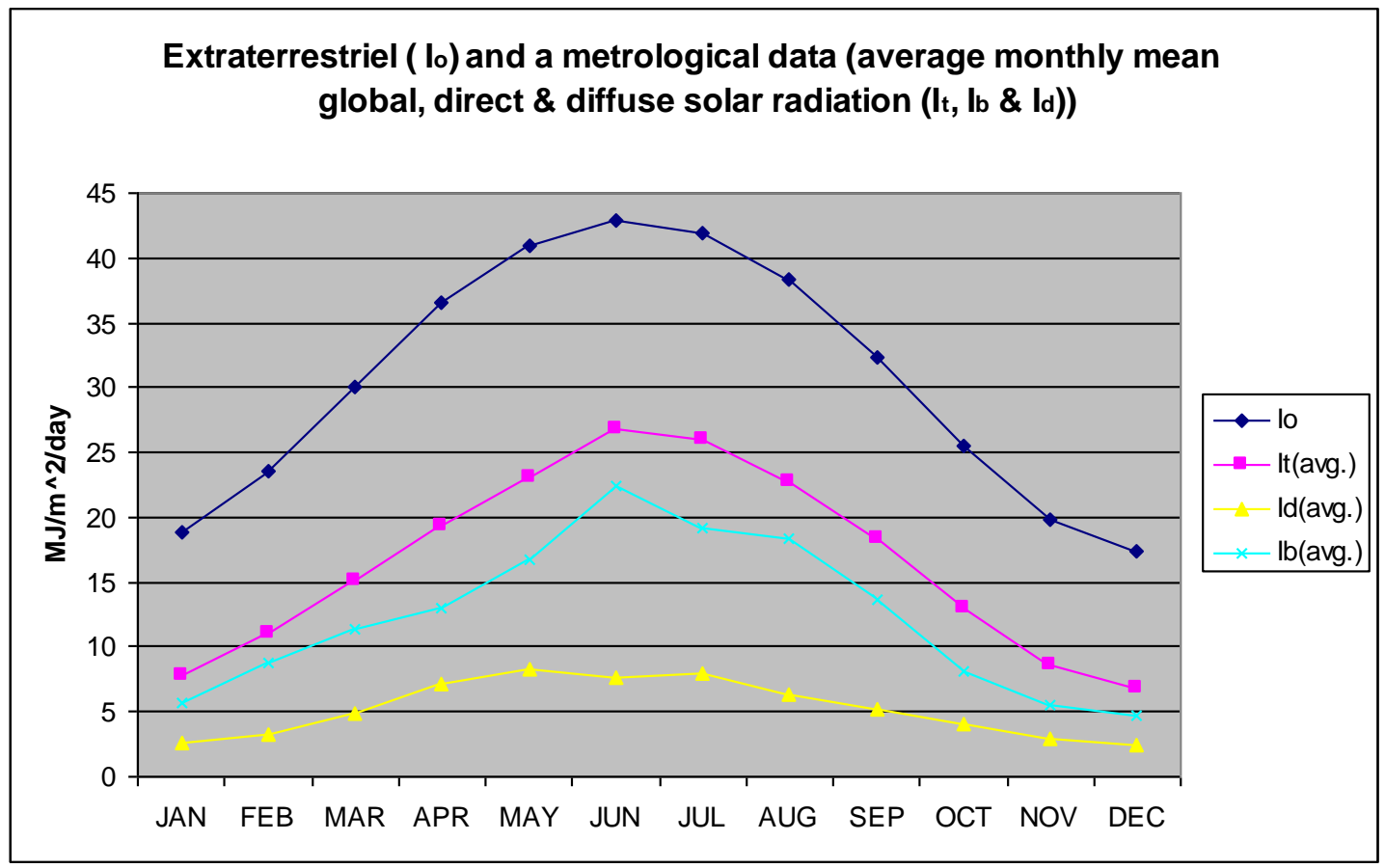

Fig. 3: Illustrated the monthly distribution of the extraterrestrial $I_{o}$ and metrological data

$$
\left(I_{t}, I_{b}, I_{o}\right)
$$

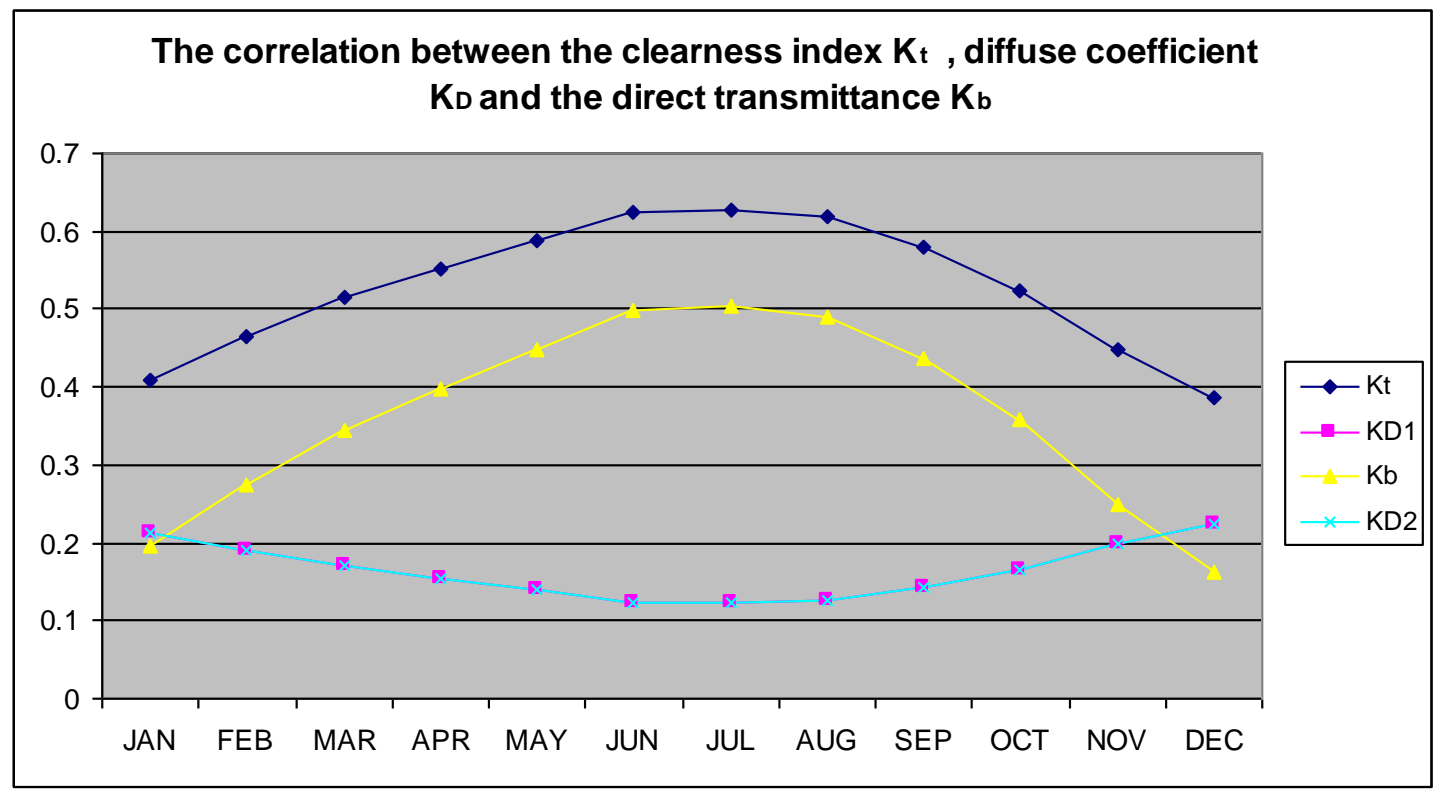

Fig. 4: Illustrated the correlation between $K_{t}, K_{D 1}, K_{D 2}, K_{b}$. 


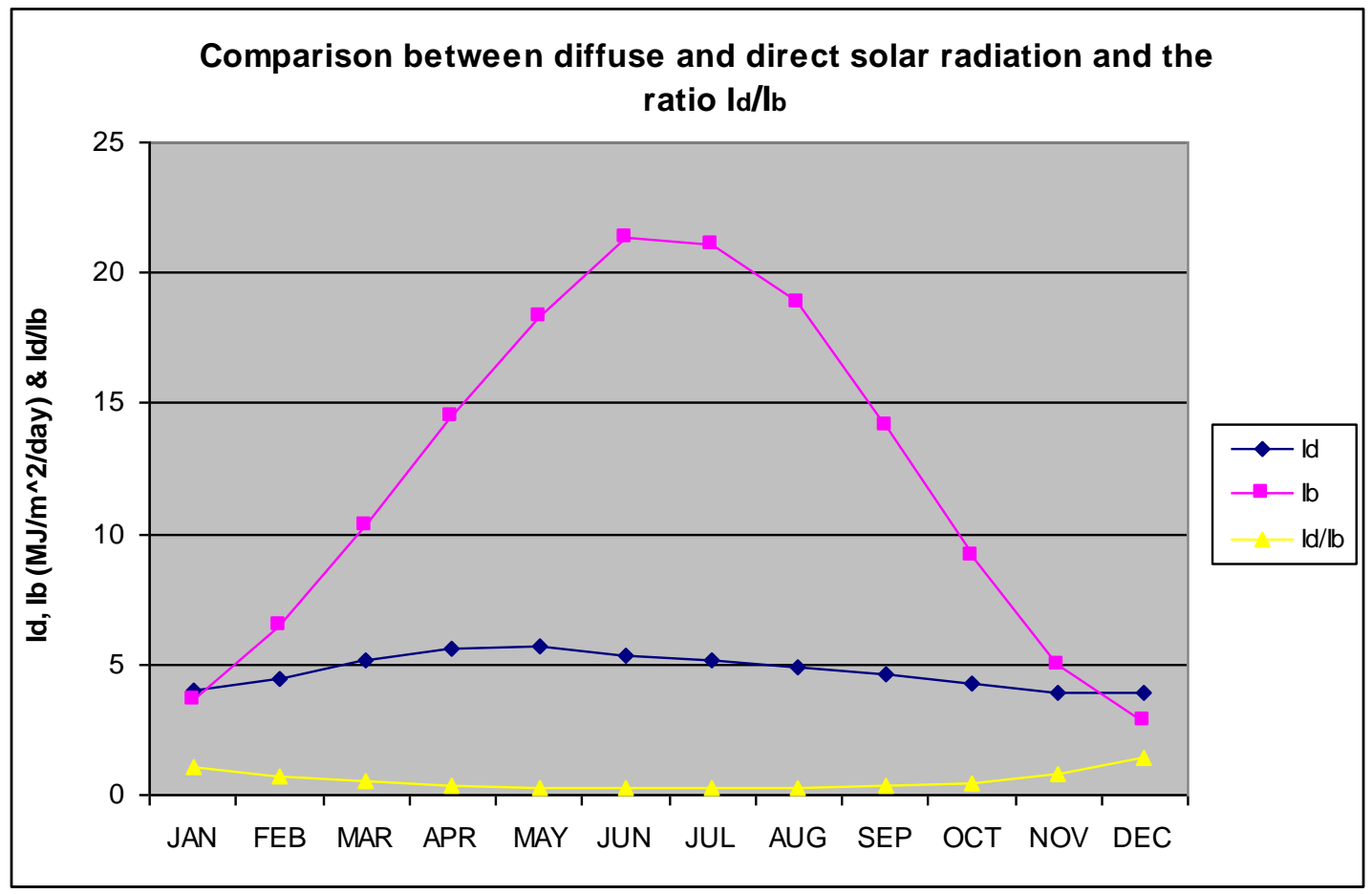

Fig. 5: Illustrated a comparison between the calculated diffuse, direct solar radiation and the ratio $I_{d} / I_{b}$.

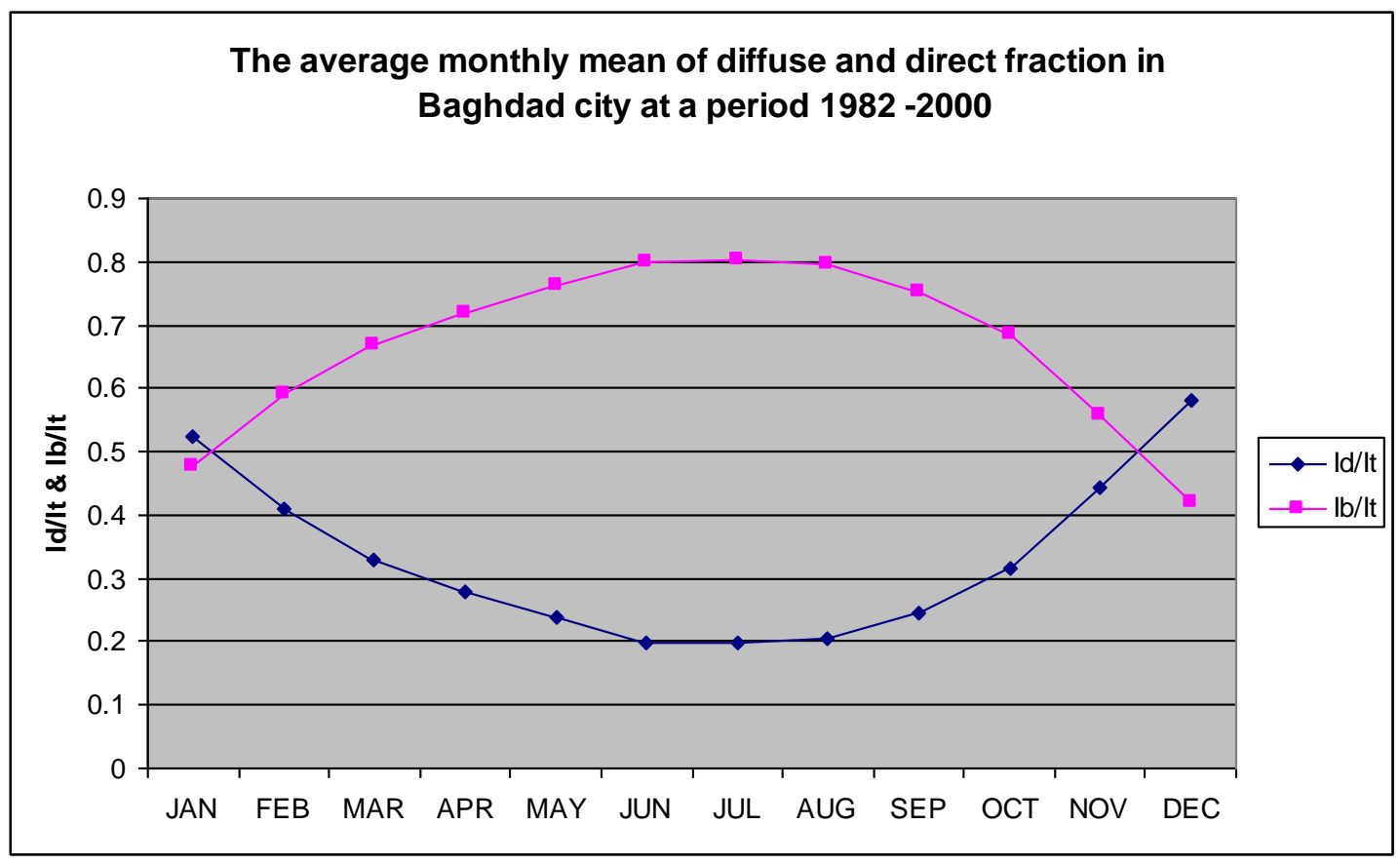

Fig. 6: Illustrated the monthly distribution between diffuse and direct fraction in Baghdad at (1982-2000). 


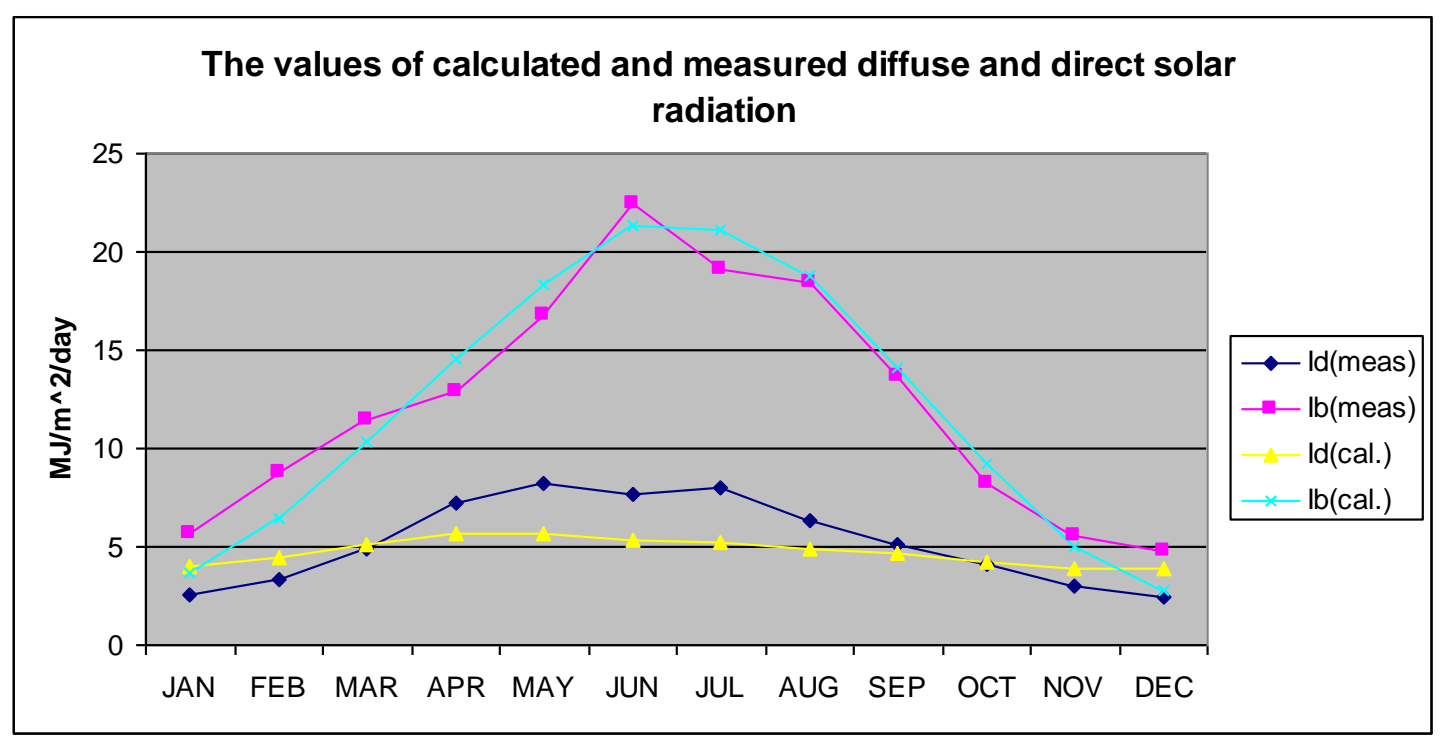

Fig. 7: Calculated and measured values of diffuse and direct solar radiation.

\section{Conclusion}

The metrological and NASA measured data of average monthly mean solar radiation of Baghdad city at a period (1983-2005) is used in this work. Liu and Jordan two models were used in this study to examine the variation of diffuse solar radiation for Baghdad.

Monthly variation of clearness index $K_{t}$, diffuse ratio $K_{D 1}, \quad K_{D 2}$ and $K_{b}$ were employed in this study to estimate the two parts (diffuse and direct solar radiation).

These models can be used in all locations selected in Iraq. The two models provide a good estimation for $I_{b}$ and $I_{d}$ for all on the horizontal surface and can be said the modelsper form well.

\section{References}

[1] E. O. Falayi and A. B. Rabiu, Solar Radiation Models and Information for Renewable Energy Applications, In Tech, University Campus STePRi Slavka Krautzeka, 2012, p.112 p.125.

[2] Kurt Spokas and Frank Forcella, Estimating Hourly Incoming Solar Radiation from Limited Meteorological Data, Weed Science 54:182-189, 2006.
[3] M. Maroof Khan and M. Jamil Ahmad, Article Estimation of global solar radiation using clear sky radiation in Yemen", Aligarh 202002, Journal of Engineering Science and Technology Review 5 (2) (2012) 12-19.

[4] L.T. Wong, W.K. Chow, Solar radiation model, ELSEVIER (Applied Energy), 69 (2001) 191-224 p. 209.

[5] Liu BYH, Jordan R C. The interrelationship and characteristic distribution of direct, diffuse and total solar radiation. Solar Energy 1960; 4(3):1-19.

[6] Akrawi, A.; Saman, W.Y. Evaluation of Heating and Cooling Degree Days in Iraq. 6th Miami international conference on alternative energy sources, Miami Beach, FL, USA, 12 Dec 1983 / Journal ID: CODEN: ALESD. Page:238.

[7] El-Sebaii and A.A. Trabea. 2005. "Estimation of Global Solar Radiation on Horizontal Surfaces Over Egypt". Egypt. J. Solids. 28 (1). 